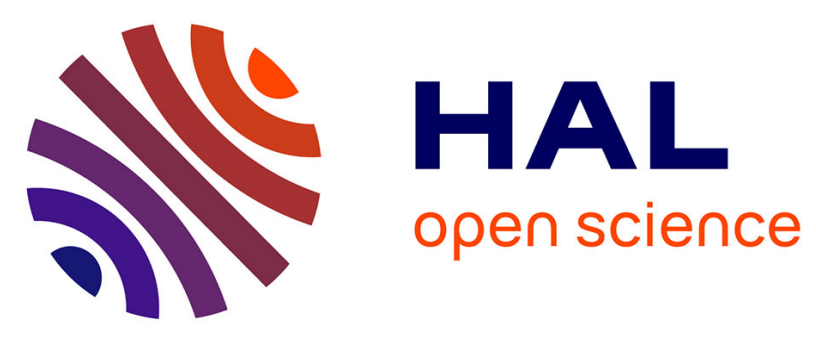

\title{
Anti-Inflammatory Activity and Cheminformatics Analysis of New Poten t 2-Substituted 1-Methyl-5-Nitroindazolinones
}

Dany Siverio-Mota, Isabel Andujar, Yovani Marrero-Ponce, Rosa Giner, Claudia Diaz-Mendoza, Ganiveth Manjarrez Paba, Liliana Vicet-Muro, Maria Lorena Cordero-Maldonado, Peter de Witte, Alexander Crawford, et al.

\section{To cite this version:}

Dany Siverio-Mota, Isabel Andujar, Yovani Marrero-Ponce, Rosa Giner, Claudia Diaz-Mendoza, et al.. Anti-Inflammatory Activity and Cheminformatics Analysis of New Poten t 2-Substituted 1Methyl-5-Nitroindazolinones. Current Topics in Medicinal Chemistry, 2018, 17 (30), pp.3236-3248. 10.2174/1568026618666180119125255 . hal-03244234

\section{HAL Id: hal-03244234 https://hal-cnam.archives-ouvertes.fr/hal-03244234}

Submitted on 1 Jun 2021

HAL is a multi-disciplinary open access archive for the deposit and dissemination of scientific research documents, whether they are published or not. The documents may come from teaching and research institutions in France or abroad, or from public or private research centers.
L'archive ouverte pluridisciplinaire HAL, est destinée au dépôt et à la diffusion de documents scientifiques de niveau recherche, publiés ou non, émanant des établissements d'enseignement et de recherche français ou étrangers, des laboratoires publics ou privés. 


\title{
Anti-Inflammatory Activity and Cheminformatics Analysis of New Potent 2-Substituted 1-Methyl-5-Nitroindazolinones
}

\author{
Dany Siverio-Mota ${ }^{1,2,3, \#}$, Isabel Andújar ${ }^{3}$, Yovani Marrero-Ponce ${ }^{1,4-6, \#, *}$, Rosa M. Giner ${ }^{3, *}$, \\ Claudia Díaz-Mendoza ${ }^{6}$, Ganiveth Manjarrez Paba ${ }^{6}$, Liliana Vicet-Muro ${ }^{1,2}$, \\ María Lorena Cordero-Maldonado ${ }^{2,7}$, Peter A. M. de Witte ${ }^{2}$, Alexander D. Crawford, ${ }^{2, *}$ \\ Maité Sylla-Iyarreta Veitía ${ }^{8}$, Facundo Pérez-Jiménez ${ }^{4}$ and Vicente J. Arán, ${ }^{9, *}$
}

\begin{abstract}
${ }^{I}$ Unit of Computer-Aided Molecular "Biosilico" Discovery and Bioinformatic Research International Network (CAMDBIR IN), Eumbayá, Quito, Ecuade Laboratory for Molecular Biodiscovery, Department of Pharmaceutical and Pharmacological Sciences, Univers Leuven, Herestraat 49, 3000 Leuven, Belgium; ${ }^{3}$ Departamento de Farmacología, Facultad de Farmacia, Universitat de València, Valencia, Spain; ${ }^{4}$ Unidad de Investigación de Diseño de Fármacos y Conectividad Molecular, Departamento de Química Física, Facultad de Farmacia, Universitat de València, Spain; ${ }^{5}$ Universidad San Francisco de Quito (USFQ), Grupo de Medicina Molecular y Traslacional (MeM\&T), Colegio de Ciencias de la Salud (COCSA), Escuela de Medicina, Edificio de Especialidades Médicas, Av. Interoceánica Km 12 1/2 - Cumbayá e Instituto de Simulación Computacional (ISC-USFQ), Diego de Robles y vía Interoceánica, Quito 170157, Ecuador; ${ }^{6}$ Fundación Universitaria Tecnológico Comfenalco - Cartagena. Grupo de Investigación Ambiental (GIA), Facultad de Ingenierías, Cartagena de Indias, Bolivar, Colombia; ${ }^{7}$ Faculty of Chemistry Sciences, School of Biochemistry and Pharmacy, University of Cuenca, Av. 12 de Abril s/n, Cuenca, Ecuador; ${ }^{8}$ Equipe de chimie moléculaire, Laboratoire de Chimie moléculaire, génie des procédés chimiques et énergétiques, EA7341, Conservatoire national des arts et métiers, 2 rue Conté, 75003 Paris, France; ${ }^{9}$ Instituto de Química Médica, CSIC, c/Juan de la Cierva 3, 28006 Madrid, Spain.
\end{abstract}

\section{A R T I C L E H I S T O R Y}

Received: February 02,2017 Revised: April 06, 2017 Accepted: November 22, 2017

DOI: ???????????????????????

\begin{abstract}
After the identification of the anti-inflammatory properties of VA5-13I (2-benzyl-1methyl-5-nitroindazolinone) in previous investigations, some of its analogous compounds were designed, synthesized and evaluated in two anti-inflammatory methods: LPS-enhanced leukocyte migration assay in zebrafish; and 12-O-tetradecanoylphorbol-13-acetate (TPA)-induced mouse ear edema. The products evaluated $(\mathbf{3}, \mathbf{6}, \mathbf{8}, 9$ and 10) showed the lower values of relative leukocyte migration at $30 \mu \mathrm{M}(0.14,0.07,0.10,0.13$ and 0.07 , respectively), while in ear edema and myeloperoxidase activity methods, all the compounds reduced inflammation, only $\mathbf{4}$ and $\mathbf{1 6}$ yielded unsatisfactory results. The relationship linking structure and activity (SAR analysis) was determinate by using SARANEA software. The importance of the 5-Nitro group of the indazole ring for the activity was evident, and showed modest reduction when benzyl (Bn) is changed by alkyl group. A substituted Bn moiety at N2 (R) is the best substituent (5-10); nevertheless, if methylene group of $\mathrm{Bn}$ is deleted, the activity is affected. Also, introduction of halogen atoms mainly at positions 3 or 4 of the benzyl moiety $(\mathbf{6}$ and 10) leads in general to strong activities. In fact, compounds 7 and $8(\mathrm{R}=4-\mathrm{FBn}$ or $4-\mathrm{ClBn}$, respectively) exhibit satisfactory results in in vivo tests and appear promising. The production of IL-6 at all doses assayed was significantly reduced, except with 16 . Nonetheless, the production of TNF- $\alpha$ was significantly inhibited only by this chemical (16) at concentration of $50 \mu \mathrm{M}$. On the other hand, compound 2 was the one that mostly inhibited the expression of COX-2 and iNOS. From these results, it can be concluded that the inhibition in the release of cytokines can be one of the mechanisms of action responsible for the anti-inflammatory effect for 2-benzyl derivates while other 2-alkyl derivatives can inhibit production of NO. Therefore, nitroindazolinone chemical prototype could be an interesting structural group with anti-inflammatory purposes in the therapeutic.
\end{abstract}

Keywords: SARANEA software, structure-activity relationship, nitroindazolinones, anti-inflammatory compound, zebrafish, TPA-induced mouse ear edema.

\footnotetext{
*Address correspondence to these authors at the Universidad San Francisco de Quito (USFQ), Grupo de Medicina Molecular y Traslacional (MeM\&T), Colegio de Ciencias de la Salud (COCSA), Escuela de Medicina, Edificio de Especialidades Médicas, Av. Interoceánica Km 12 1⁄2 Quito 170157, Ecuador; Tel: +593-2-297-1700 (ext. 4021); E-mails: ymarrero@usfq.edu.ec or ymarrero77@yahoo.es, Rosa.M.Giner@uv.es, alexander.crawford@pharm.kuleuven.be, vjaran@iqm.csic.es

\#These authors contributed equally to this work.
} 


\section{INTRODUCTION}

Inflammation is a nonspecific process in response to external aggressions which consist of a sequence of immunological and physiological reactions against noxious stimuli like irritants, pathogens or damaged cells [1]. When the body is not able to stop this acute inflammatory response, it extends in time, turning into a chronic inflammation in which processes of tissue damage coexist with repair attempts [2]. Osteoarthritis [3], rheumatoid arthritis [4], Alzheimer's disease [5] and cancer [2] are some examples of this unregulated immune response of the organism against its own tissues.

Cytokine networks regulate this inflammatory response. For example, the pro-inflammatory cytokines tumor necrosis factor $\alpha$ (TNF- $\alpha$ ) and interleukin 6 (IL-6), have intense effects on the regulation of immune reactions and inflammation. However, non regulated production of these cytokines has a critical function in the development of many inflammatory diseases [6].

Also the induction of other pro-inflammatory mediators, including nitric oxide (NO) and prostaglandins (PGs) produced by the inducible isoform of nitric oxide synthase (iNOS) and cyclooxygenase-2 (COX-2) enzymes, respectively $[6 \mathrm{~b}, 7]$, is directly involved in the control of the immune response. Based on the biochemical and the physical characteristics of the purified enzymes, three isoforms of NOS (types I, II, and III) have been described in mammalian cells. Type I (neuronal NOS, nNOS) and type III (endothelial NOS, eNOS) have been categorized as constitutive NOS (cNOS) because these are constantly present in the cells, although type II (identified as iNOS), is expressed only after exposure to specific stimuli such as cytokines, bacterial endotoxin lipopolysaccharide (LPS), and calcium ionophores [8].

COX enzyme transforms arachidonic acid to prostaglandin (PGs). Like NOS, COX exists in three isoforms, and COX-2 -inducible form triggered by different stimuli such as growth factors or interleukin-1 (IL-1),- is responsible for the fabrication of huge quantities of pro-inflammatory PGs at the inflammatory site [9]. Consequently, the inhibition of pro-inflammatory mediator production signifies a critical target for the screening of anti-inflammatory compounds [10]. The majority of non-steroidal anti-inflammatory drugs (NSAIDs) inhibit COX isozymes to different degrees, which accounts for their anti-inflammatory properties as well as their gastrointestinal side effects.

Nonetheless, the COX enzymes are not the only target of NSAIDs. Recently, Peretz et al. [11] showed that NSAIDs also act as openers of Kv7.2/3 (KCNQ2/3) potassium channels [12]. Pharmacological targeting of these potassium channels -M-channels- is of great clinical importance. While openers exhibit a therapeutic potential for the treatment of neuronal hyper-excitability like epilepsy, migraine and neuropathic pain are potentially advantageous for the treatment of memory problems and Alzheimer's disease [1112].

Worldwide morbidity rates influence the widespread use of anti-inflammatory drugs for the treatment of both acute and chronic conditions. Pharmacological selection of the therapeutic agent is mainly conditioned by the severity of the side gastrointestinal effects like dyspepsia, gastric erosions, ulcerations, and bleeding. The incidence and severity of these problems increase as the treatment is continued in time, mainly due to chronified inflammatory diseases [13]. The wide use and the disadvantages of the existing antiinflammatory therapy drive the search for new efficient and innocuous drugs [14].

In the preceding study, we evaluated the antiinflammatory activity of a set of nitroindazolinone chemotype chemicals by in silico and in vivo methods [15]. In this sense, the TOMOCOMD-CARDD (TOpological MOlecular COMputational Design-Computer Aided "Rational" Drug Design) descriptor was used to request a quantitative structure-activity relationship (QSAR)-based ensemble classifier, for anti-inflammatory drug-like compounds from a dissimilar series of chemicals. The above-mentioned quadratic indices molecular descriptors [16] for large series of active/nonactive products were calculated and then linear discriminate analysis was used to fit every individual classification function. A multi-agent QSAR classification system (ensemble classifier) was developed and used for the identification of a new anti-inflammatory lead-like by means of ligand-based virtual screening of small-molecules available. In this ensemble classifier, the individual QSAR outputs are the inputs of the above-mentioned fusion approach [15].

The in silico studies and two in vivo assays using Danio rerio (zebrafish) larvae and rodents as models were used to evaluate the anti-inflammatory activity.

In this study, compounds 1-benzyl-2-methyl-5nitroindazolinone (VA5-13h), 2-benzyl-1-methyl-5nitroindazolinone (VA5-13I) and 2-benzyl-1-pentyl-5nitroindazolinone (VATR-4) displayed anti-inflammatory properties, giving evidence of the potential of these structures as novel drug candidates (see Fig. 1) [15]. Furthermore, these compounds displayed anti-inflammatory activity in a rat paw edema model [17]. The results established that VA5131 containing an innovative chemotype is a new antiinflammatory lead and represents an important therapeutic alternative for the treatment of inflammatory processes.

In the present work, we have studied the effects of different analogs of VA5-13I on in vivo anti-inflammatory assays (zebrafish leukocyte migration model and auricular edema in mice) and on in vitro assays (TNF- $\alpha$ release, IL-6, LPSinduced nitric oxide, as well as expression of iNOS and COX-2 enzymes in the macrophage cell line RAW 264.7). Finally, using the concept of an activity landscape with SARANEA software, we explored the structure-activity relationship (SAR) information [18].

\section{RESULTS AND DISCUSSION}

Considering the anti-inflammatory activity described for VA5-131 in a previous report [15], in the present article, we describe the anti-inflammatory activity of some novel derivatives (see Table $\mathbf{1}$ and Fig. 1) of this compound using in vivo and in vitro tests. These nitroindazolinones (1,2disubstituted 5-nitroindazolin-3-ones) have a methyl group at position 1 and different substituents at position 2 (aryl, alkyl, substituted benzyl, etc.) and were earlier synthesized by us based on their expected antichagasic properties [19]. 
Table 1. Chemical structure of VA5-13I analogs.

\begin{tabular}{|c|c|c|}
\hline No. & Compound & $\mathbf{R}$ \\
\hline 1 & VATR-6 & $\mathrm{Nm}$ \\
\hline 2 & VATR-9 & $\mathrm{Me}$ \\
\hline 3 & VATR-12 & $\mathrm{Ph}$ \\
\hline $4^{*}$ & VATR-33 & $\mathrm{Bn}$ \\
\hline 5 & VATR-36 & 2-FBn \\
\hline 6 & VATR-37 & 3-FBn \\
\hline 7 & VATR-38 & 4-FBn \\
\hline 8 & VATR-41 & 4-ClBn \\
\hline 9 & VATR-42 & $2-\mathrm{BrBn}$ \\
\hline 10 & VATR-44 & 4-BrBn \\
\hline 11 & VATR-51 & 3-CNBn \\
\hline 12 & VATR-54 & $3-\mathrm{F}_{3} \mathrm{Bn}$ \\
\hline 13 & VATR-55 & $4-\mathrm{CF}_{3} \mathrm{Bn}$ \\
\hline 14 & VATR-60 & 2-PhBn \\
\hline 15 & VATR-62 & $3-\left(\mathrm{COOCH}_{3}\right) \mathrm{Bn}$ \\
\hline 16 & VATR-64 & $\mathrm{Cy}$ \\
\hline 17 & VATR-65 & 2-MeOBn \\
\hline 18 & VATR-66 & $\alpha-\mathrm{MeBn}$ \\
\hline 19 & VATR-45 & 3-MeOBn \\
\hline
\end{tabular}

"Without $\mathrm{NO}_{2}$ group. Nm: 2-Naphthylmethyl, Ph: Phenyl, Bn: Benzyl, Cy: Cyclohexylmethyl

All chemicals were evaluated in a primary antiinflammatory screening via zebrafish larvae assay [20]. The more active compounds were tested in 12-O-tetradecanoylphorbol-13-acetate (TPA)-induced ear edema in mouse. Finally, the evaluation of the production and expression of pro-inflammatory mediators and enzymes associated with the inflammatory process was carried out in order to establish a potential mechanism of action.

\subsection{First Evaluation and Rapid Screening Using LPS- Enhanced Leukocyte Migration Towards Tail Injury}

Zebrafish is a biological model used to investigate illness and anomalies that frequently affect higher animals and human beings [21]. In this study, the assessment of leukocyte migration to damaged zones in zebrafish larvae was used as a primary test to evaluate the anti-inflammatory properties of the compounds in question. First, the maximum tolerated concentration (MTC) for each compound was determined, using $100 \mu \mathrm{M}$ as the highest tested concentration. Optical visualization of zebrafish larvae subjected to compound treatment allowed the determination of toxic signs, e.g. pericardial edema, changes in heartbeat, loss of normal posture and death.

Numerous compounds were toxic or insoluble at concentrations above of $30 \mu \mathrm{M}$. Consequently, concentrations of 30 and $10 \mu \mathrm{M}$ were the doses used for the anti-inflammatory screen. Nevertheless, some products (namely, 1 and 14) were insoluble even at $30 \mu \mathrm{M}$ (see Table 2 , NT symbol). In view of these results, the concentrations for the assay were established for each substance and the anti-inflammatory activity was evaluated following the guidelines of the LPS-enhanced leukocyte migration assay [20]. Low values of relative leukocyte migration $[R L M$, cut-off $\leq 0.5)$ ] to damaged areas were considered as a proof of anti-inflammatory activity. The evaluation of RLM is reported in Table 2.

In general, compounds containing halogen-substituted benzyl groups at position 2 in the indazole ring showed the lower values of RLM (see next section). Values of 0.09 and 0.07 at 10 and $30 \mu \mathrm{M}$, respectively, were yielded by compound $6(\mathrm{R}=3-\mathrm{FBn})$. In addition, $3(\mathrm{R}=\mathrm{Ph}), 8(\mathrm{R}=4$ $\mathrm{ClBn}), 9(\mathrm{R}=2-\mathrm{BrBn})$, and $10(\mathrm{R}=4-\mathrm{BrBn})$ showed good anti-inflammatory activity at $30 \mu \mathrm{M}$ with RLM values of $0.14,0.10,0.13$, and 0.07 , respectively, in comparison with 0.16 that is the value of the positive control, indomethacin $100 \mu \mathrm{M}$, and 0.15 that is the value attained by VA5-13I. On the other hand, compound 4, without 5- $\mathrm{NO}_{2}$ group, displayed a high value of leukocyte migration at $30 \mu \mathrm{M}(0.48)$, which was close to cutoff point for a significant anti-inflammatory activity (0.5), suggesting that maybe the presence of this
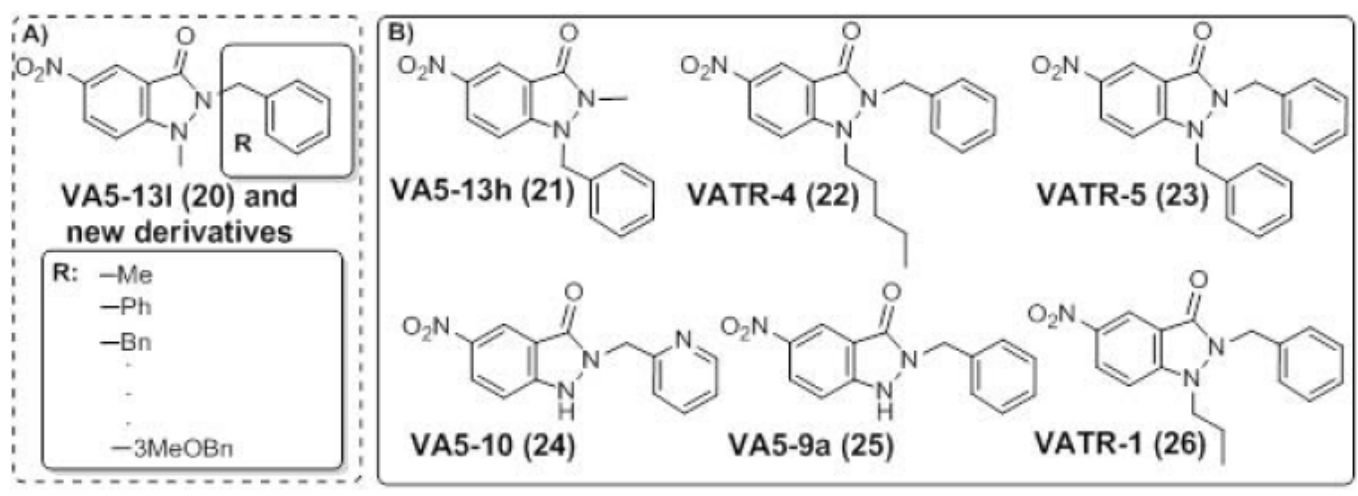

Fig. (1). Chemical structure and scaffold optimization: A) New analogs of VA5-13I (compound 20) and B) 5-nitroindazolinones with antiinflammatory activity (compounds 21-26) [15]. 
Table 2. Activity of compounds tested in the LPS-enhanced leukocyte migration assay in zebrafish.

\begin{tabular}{|c|c|c|c|c|c|}
\hline No/Name ${ }^{a}$ & \multicolumn{5}{|c|}{ RLM/Concentration $(\mu \mathrm{M})$} \\
\hline 2 VATR-9 & - & - & - & 0.31 & 0.10 \\
\hline 3 VATR-12 & - & - & 0.37 & 0.14 & $\mathrm{~T}$ \\
\hline 5 VATR-36 & - & - & - & - & - \\
\hline 6 VATR-37 & - & - & 0.09 & 0.07 & $\mathrm{~T}$ \\
\hline 7 VATR-38 & - & - & - & - & - \\
\hline 11 VATR-51 & - & - & - & 0.70 & 0.38 \\
\hline 12 VATR-54 & - & - & 0.59 & 0.37 & $\mathrm{~T}$ \\
\hline 13 VATR-55 & - & - & - & - & - \\
\hline 14 VATR-60 & 0.37 & 0.51 & $\mathrm{~T}$ & NT & NT \\
\hline 15 VATR-62 & - & - & 0.39 & 0.23 & $\mathrm{~T}$ \\
\hline 16 VATR-64 & - & - & 0.47 & 0.21 & $\mathrm{~T}$ \\
\hline 17 VATR-65 & - & - & 0.34 & 0.21 & NT \\
\hline 22 VATR-4 & 0.68 & 0.67 & 0.27 & NT & NT \\
\hline 23 VATR-5 & 0.58 & 0.65 & 0.25 & NT & NT \\
\hline 24 VA5-10 & - & - & 0.94 & 0.62 & 0.66 \\
\hline 25 VA5-9a & - & - & 0.81 & 0.65 & 0.39 \\
\hline 26 VATR-1 & - & 0.89 & 0.86 & 0.16 & $\mathrm{~T}$ \\
\hline Indomethacin "B" & 0.54 & 0.50 & 0.48 & 0.38 & 0.28 \\
\hline
\end{tabular}

${ }^{a}$ The molecular structures of the compounds represented with "number-wordcode" are shown in Table $\mathbf{1}$ and Fig. (1). T, toxic concentration for zebrafish and NT, not tested due to problems of solubility in Danieau's medium. Chemicals $5(2-\mathrm{FBn}), 7(4 \mathrm{~F}-\mathrm{Bn})$ and $\mathbf{1 3}\left(4-\mathrm{CF}_{3} \mathrm{Bn}\right)$ were not tested in this first step, because they were selected latter due to the good results of their close-relate derivatives. The RLM values for compounds 21-26 and "Indomethacin B" were taken from reference [15].

$\mathrm{NO}_{2}$ group is advantageous for anti-inflammatory activity. Compound 1 showed very good anti-inflammatory activity with RLM values of 0.09 and 0.08 at 10 and $3 \mu \mathrm{M}$, respectively. However, concentrations above $10 \mu \mathrm{M}$ were insoluble in the assay medium possibly due to the high lipophilicity conferred by its 2-naphthylmethyl moiety (see Fig. 1 and Tables 1-2).

\subsection{SARANEA-based SAR Analysis}

Network-like Similarity Graph (NSG), a graphical structure-activity relationship (SAR) analysis method, [18], has been used to search for SAR information in compound data sets by means of SARANEA software [18a]. This method allows us to study the relation between global and local SAR features across to NSGs that represent an annotated NSG 


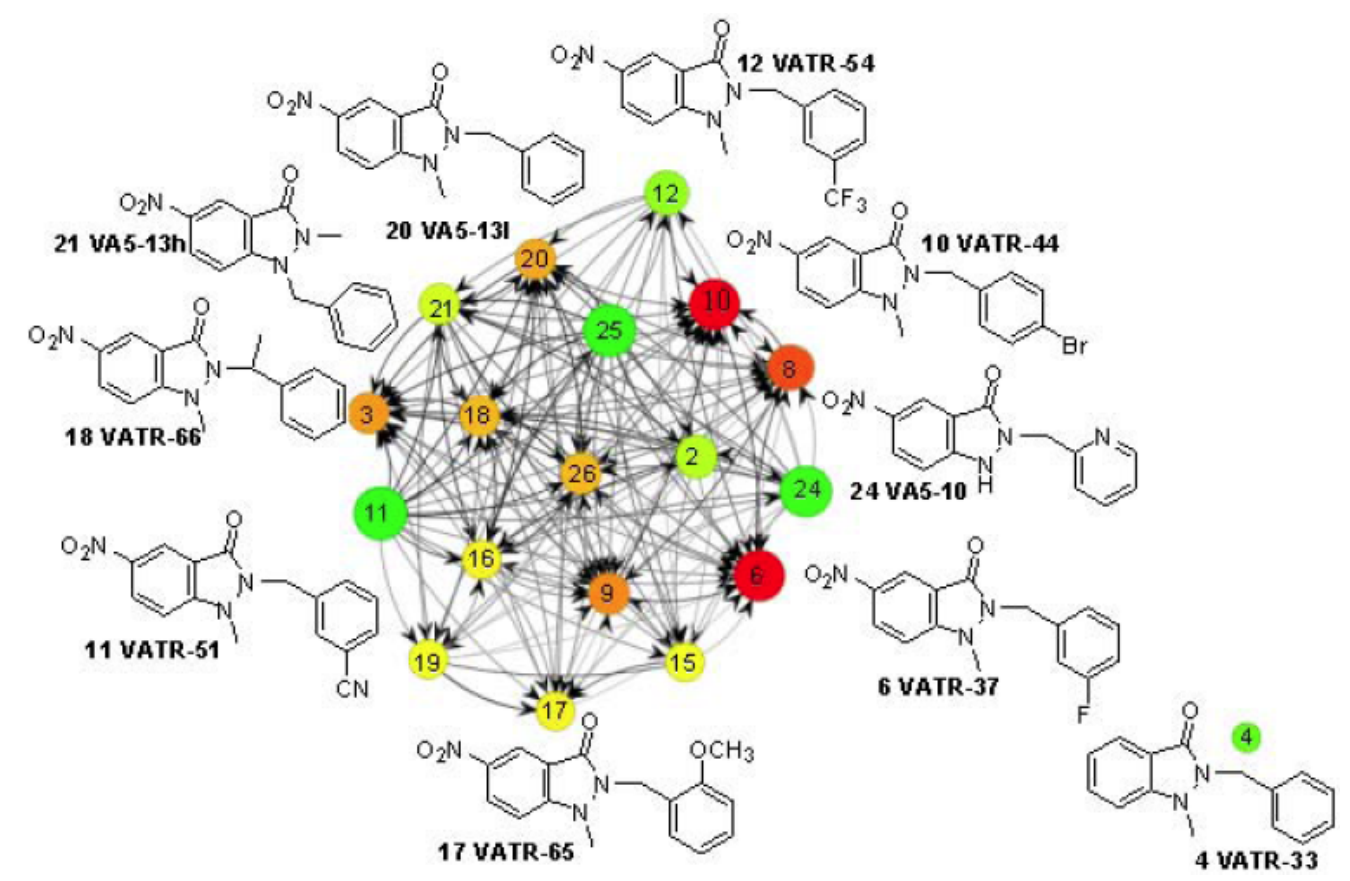

Fig. (2). Network-like Similarity Graph (NSG) created with SARANEA. Nodes signify compounds, and edges are drawn between them if pairwise MACCS Tc values are $>0.75$. Nodes are color-coded agreeing to potency using a continuous spectrum from green (lowest potency) to red (highest potency). The node's size represents the compound discontinuity score, and areas containing large red nodes indicate "activity cliffs". Compounds 21-26 (structure and RLM values) are taken from reference [15] (see Fig. 1).

structure integrating different levels of SAR-relevant chemical information.

Each molecule is represented by a node, and the nodes are connected by edge if the structural similarity of two compounds exceeds a threshold value. Fig. (2) illustrates the NSG for our new compounds. However, in this study we also included the most potent 5-nitroindazolinone-based antiinflammatory compounds (chemicals 21-26 in Fig. 1 and Table 2) in reference [15].

As can be seen in Fig. (2), nodes are color-coded by the potency value (RLM at $30 \mu \mathrm{M}$ ) of the chemicals characterized by a continuous spectrum from green (lowest potency) to red (highest potency).

The size of each node is scaled agreeing to the local discontinuity score of chemicals (i.e., the higher score, the larger node). The areas containing large red nodes signify "activity cliffs" (see below). That is the case of compounds 6 (VATR-37) and 10 (VATR-44) (discontinuity of 0.37 for both, see Table 3 ), which are the most potent compounds, but their potency significantly deviates from that of their structural neighbours. In fact, nodes $\mathbf{6}$ and $\mathbf{1 0}$ (red) have edges with numerous green (low-to-moderate potency) nodes. These pair connected nodes represent structurally similar chemicals with huge potency differences that form an "activity cliff" [18], that is, a region of highest local SAR discontinuity (see Table 3 and Fig. 2).

The SAR index (global SARI) is a numerical function used to assign a SAR category to a given set of chemicals. Possible values range from 0 to 1 , and low, intermediate, and higher values represent three diverse SAR categories, discontinuous, heterogeneous, and continuous SARs, correspondingly. Score calculations are based on compound simi- larity and potency values. Here, our set shows a SARI value of 0.515 , that is, a heterogeneous SAR. Such heterogeneous SAR corresponds to the presence of "variable activity landscapes", i.e., the combination, or coexistence, of continuous and discontinuous SAR components.

Fig. (3 and Table 3) depicts the SAR pathway where some continuous SARs can be noticed. This "tree method", on the basis of the NSG data structure, searches for sequences of pairwise similar chemicals that display a regular increase in potency along the sequence. The endpoint of this tree was compound $\mathbf{6}$, and the first node was selected by SARANEA program from all chemicals chosen in neighborhood of compound $\mathbf{6}$. This software feature allowed the exploration of structural variations that result in an increase in potency (see Fig. 3 and Table 3). Nonetheless, layered chemical neighborhood graph is exposed in Fig. (4) in order to organize chemicals with decreasing similarity to the central molecule designated (compound 20) from this pathway. In this figure, the chemicals are projected on concentric circles that signify levels of decreasing similarity relative to the central reference compounds, in this case the starting compound 20 (VA5-13I).

From these studies (see Figs. 2-4), we can infer some relevant conclusions about structure-activity relationship. First of all, it is clear that the effect of substituent on the antiinflammatory activity depends on the structure of the different moieties at position 2. If a methyl group (2) is replaced by a phenyl group (3) the activity increases; but the latter substitution increases after introduction of a Bn group in $\mathbf{2 0}$ (VA5-13I). As commented above, the 5-nitro group of the indazole ring has a crucial function in the anti-inflammatory effect; in fact, compound 4, without-5-nitro group presents a low activity and is a singleton in Fig. (2). Moreover, the 
Table 3. Some features and function values from SARANEA program. ${ }^{a}$

\begin{tabular}{|c|c|c|c|c|c|}
\hline ID $^{\mathrm{b}}$ & Name $^{b}$ & Potency $^{\mathrm{c}}$ & Discontinuity & Tanimoto coef. & Cliff Index \\
\hline 10 & VATR-44 & 0.07 & 0.37 & 1 & Infinity \\
\hline 3 & VATR-12 & 0.14 & 0.2 & 0.92 & 1.11 \\
\hline 9 & VATR-42 & 0.13 & 0.2 & 1 & 1.08 \\
\hline 18 & VATR-66 & 0.16 & 0.18 & 0.93 & 1.34 \\
\hline 11 & VATR-51 & 0.7 & 0.42 & 0.92 & 3.68 \\
\hline 26 & VATR-1 & 0.16 & 0.18 & 0.93 & 1.34 \\
\hline 19 & VATR-45 & 0.23 & 0.17 & 0.86 & 1.79 \\
\hline 8 & VATR-41 & 0.1 & 0.26 & 0.97 & 0.6 \\
\hline 25 & VA5-9a & 0.65 & 0.4 & 0.93 & 3.62 \\
\hline 2 & VATR-9 & 0.31 & 0.21 & 0.9 & 2.33 \\
\hline 12 & VATR-54 & 0.37 & 0.25 & 0.92 & 2.67 \\
\hline 24 & VA5-10 & 0.62 & 0.36 & 0.89 & 3.38 \\
\hline 17 & VATR-65 & 0.21 & 0.16 & 0.86 & 1.65 \\
\hline
\end{tabular}

${ }^{\mathrm{a}}$ Starting from neighborhood of compounds $\mathbf{6}$ and 10. ${ }^{\mathrm{b}}$ The molecular structures of the compounds represented with numbers and codes are shown in Table 1 . Chemicals from $\mathbf{2 1 - 2 6}$ were the most potent 5-nitroindazolinone-based anti-inflammatories in reference [15] (see also Figs. 1 and 2). ${ }^{\mathrm{C}}$ Activity (RLM) at $30 \mu \mathrm{M}$.

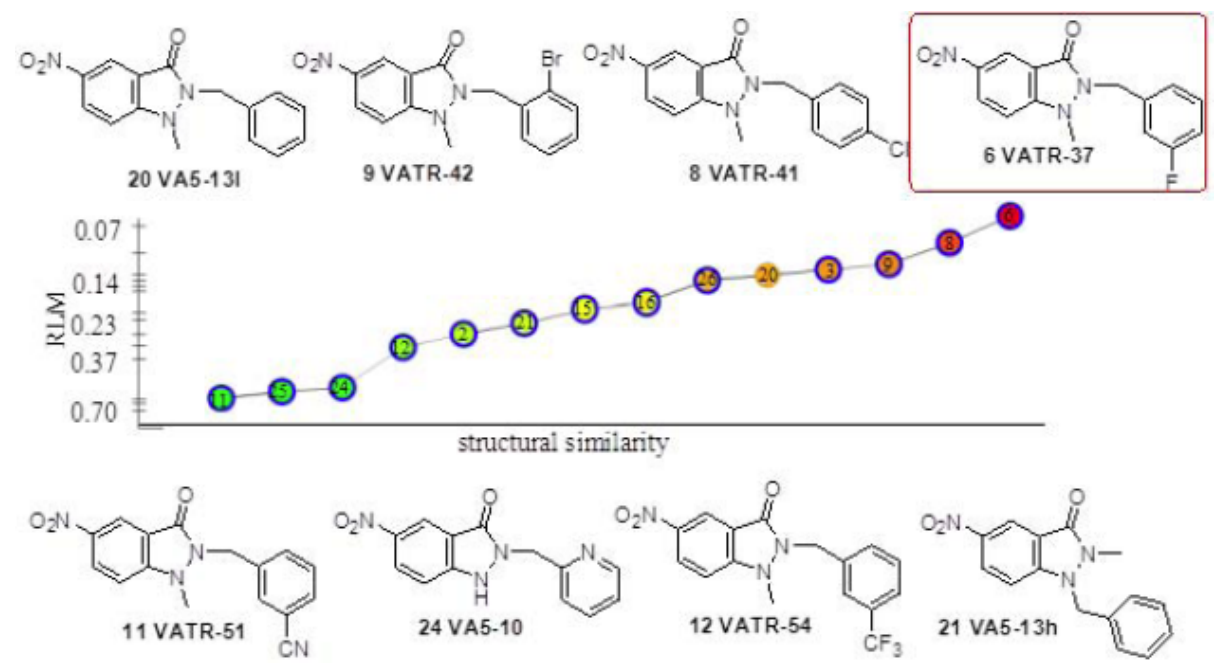

Fig. (3). Pathway or SARtree from new lead 20 (VA5-13I). The structure of eight chemicals signified by individual nodes in the all spectrum of tree, are exposed (compound and node numbers correspond). At the bottom (left), green nodes characterize compounds with low potency. At the top (right), red nodes $(\mathbf{3}, \mathbf{9}, \mathbf{8}$, and $\mathbf{6}$ ) characterize pathway endpoints, i.e., chemicals with high potency. All sequence in the pathway try to visualize the small structural modifications that are complemented by a regular change in potency. Compounds 21-26 (structure and RLM values) are taken from reference [15] (see Fig. 1).

substitution of $\mathrm{Bn}$ group in compound $\mathbf{2 0}$ by other alkyl moieties (2: $\mathrm{CH}_{3}$, 16: cyclohexylmethyl and 18: $\alpha-\mathrm{CH}_{3} \mathrm{Bn}$ ) modestly reduced the activity.
Among the compounds, a Bn moiety at N-2 is the best substituent (5-10); nevertheless, if a methylene group of the $\mathrm{Bn}$ is absent, the activity is roughly influenced, as can be 


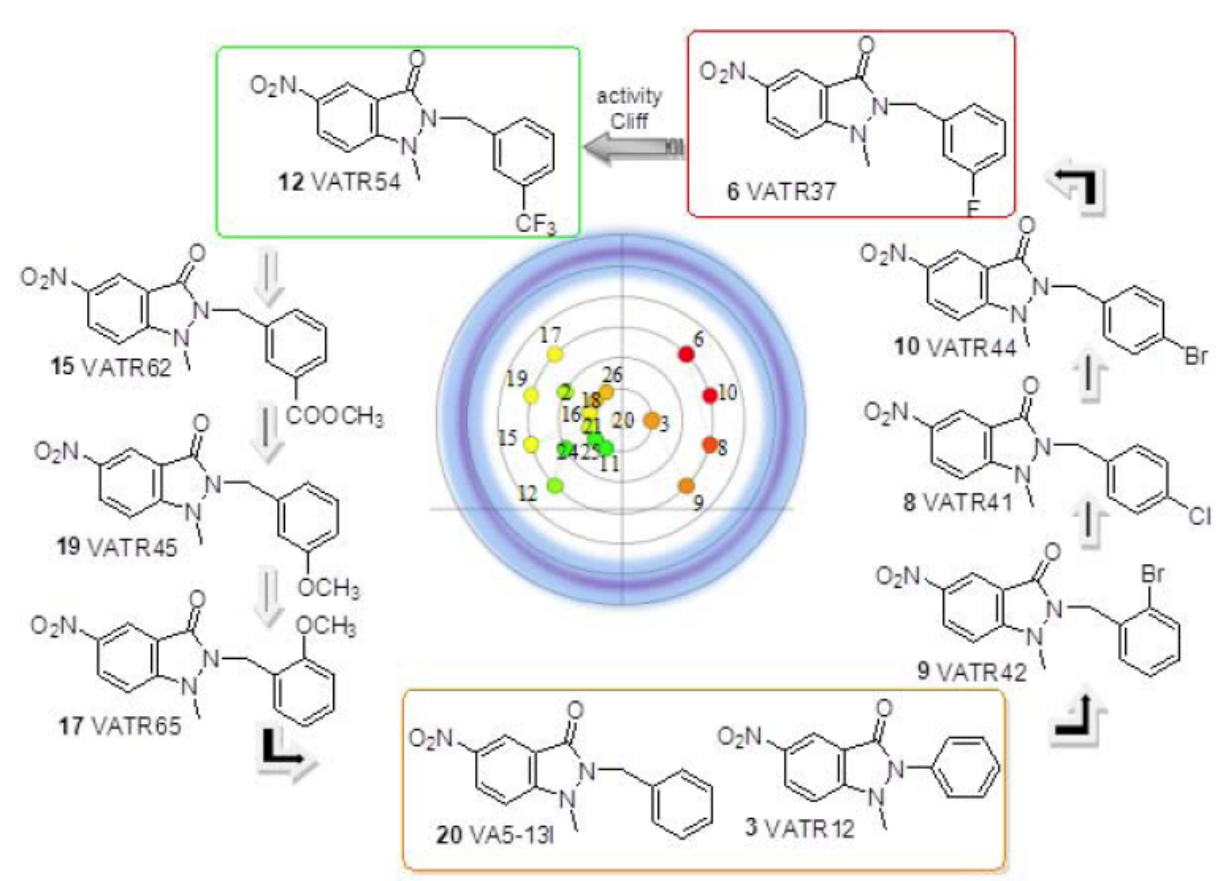

Fig. (4). Exploring chemical neighborhoods. The chemical neighborhood of parent molecule 20 (VA5-13I) is explored by this layer-based graph explores. The neighbors of compound 20, are situated on concentric circles representing different levels of structural similarity. Most similar compounds are located on the innermost circle, and nodes indicating structurally increasing dissimilar compounds are placed on subsequent peripheral circles. Nodes on the right side of the vertical line characterize chemicals with higher potency that our central node, whereas chemicals corresponding to vertices on the left side are less potent. The chemical structures from $3^{\text {rd }}$ layer, where the most potent compound $\mathbf{6}$ is included, are exposed. The pathway is leading from a continuous local SAR to a discontinuous region, for instance, from $\mathbf{6}$ to 12 ("activity cliff").

observed in the effect of 2-phenyl derivative $3 \mathrm{vs}$. that of 2benzyl analog 20.

Introduction of halogen atoms mainly at positions 3 or 4 of the Bn moiety (6 and 10) leads in general to robust activities. It is rather important to notice that the effect of compounds containing some other electron-withdrawing groups such as those found in compounds 11-13 and $15\left(-\mathrm{CN},-\mathrm{CF}_{3}\right.$, $-\mathrm{COOCH}_{3}$ ), was lower than those of the halogen analogs 6 and 10. On the other hand, bulky groups in Bn moiety $(\mathbf{1 4}, \mathbf{1})$ enhanced toxicity and slightly decreased the antiinflammatory activity.

In addition, the most potent compounds $\mathbf{6}$ and $\mathbf{1 0}$ (right side in Fig. 4) form "activity cliffs" with several compounds. For instance, compound $\mathbf{3}$ and the other two products $(\mathbf{8}$ and 9) represent a steep "activity cliff" because they are structurally very similar to the central molecule 20 but show significantly lower $(\mathbf{2 6}, \mathbf{1 8}, \mathbf{1 1}, \mathbf{2 5}$ and $\mathbf{2 1}$, etc) potency. Compounds in different similarity layers are also compared. For example, compounds 17, 19, 15, 12 are located in the last and compounds $\mathbf{2}$ and $\mathbf{2 4}$ are positioned in the second layer of the graph.

Other features can be extracted from Figs. (3 and 4), where compounds are ranked on the basis of their fit to the SAR model. This model consists of as many as possible pairwise similar compounds following an ideally linear potency gradient with small potency increases between subsequent compounds. As can be seen in Fig. (3), there is SAR continuity in data set generated. However, this pathway connects regions of SAR continuity with an "activity cliff" as shown in Figs. (3 and 4).

\subsection{In Vivo Experimental Corroboration using Mouse Ear Edema Test for More Potent Compounds}

Taking into consideration the importance of an in vivo analysis when studying the anti-inflammatory activity, we assayed the selected compounds in a mouse model of acute ear edema induced by topical application of a single dose of 12-O-tetradecanoylphorbol-13-acetate (TPA). Despite its lack of specificity, this test is a good research model for initial studies and gives relevant biological data about the antiinflammatory effect of a compound in question.

A single application of TPA in mouse ears rapidly causes edema and erythema that reach a maximum $6 \mathrm{~h}$ after application and disappear within $24 \mathrm{~h}$ [22]. Edema was determined as the difference in weight between the left and right ear (that is, TPA-treated and untreated ear). As shown in Fig. (5A), all tested compounds showed anti-inflammatory activity with more than $75 \%$ inhibition of edema compared to the control group, which only received TPA. The compounds 7 , 8, 12 and 16 showed inhibition values similar to those of indomethacin $(92 \%)$, the positive control.

Myeloperoxidase (MPO) is an enzyme contained in the azurophilic granules of neutrophils, and it can be used as a marker for the influx of polymorphonuclear leucocytes into the inflammation site [23]. As shown in Fig. (5B), all compounds, except 4 and 16, significantly decreased neutrophil infiltration, determined as MPO activity, on TPA test. Compound 4, without $5-\mathrm{NO}_{2}$ group, showed values lower than those of other compounds, although the edema inhibition was similar to the other tested compounds. This compound without $\mathrm{NO}_{2}$ group did not inhibit neither the auricular 
edema nor MPO activity [15]. This suggests that the presence of $\mathrm{NO}_{2}$ in position 5 is favorable for anti-inflammatory activity.

A disclosure from these results was compound 6 (more potent in zebrafish model), which showed moderate activities in both assays on mouse ear edema. Compound 8 (4$\mathrm{ClBn}$ derivative) showed the highest potency in both tests. The corresponding 4-FBn analog 7 was also rather potent (see Fig. 5).

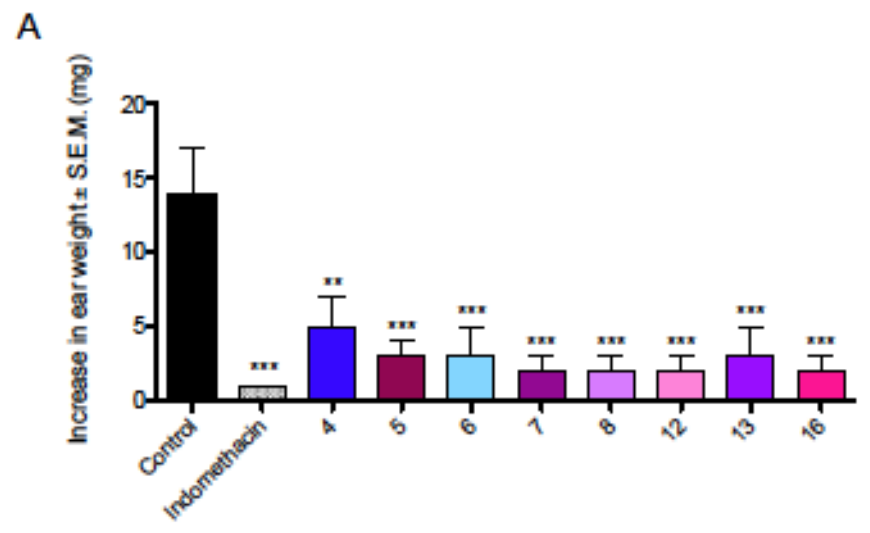

B

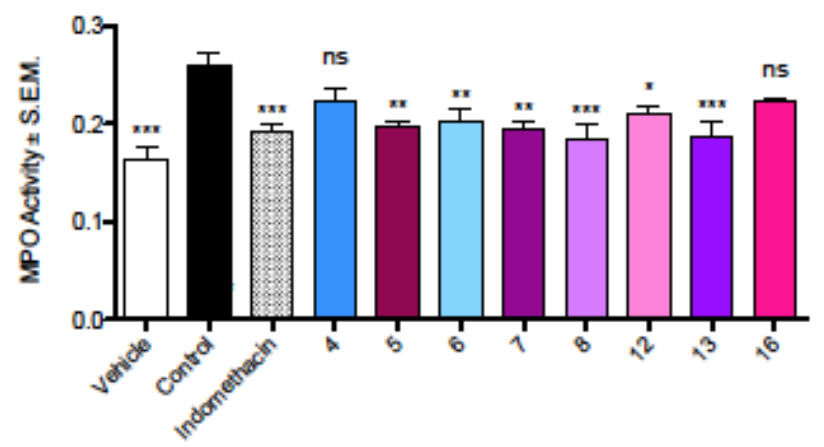

Fig. (5). Inhibitory effect of the selected compounds on TPAinduced ear edema and on MPO activity. (A) Edema was evaluated after $4 \mathrm{~h}$ of TPA application; values are expressed as the increase in ear weight \pm standard error of the mean (S.E.M.), $n=6$ (B) Effect on MPO activity. MPO was measured in tissue homogenates of the ears and it is expressed as Activity \pm S.E.M. Statistical analysis was accomplished using one-way analysis of variance followed by Dunnett's $t$-test. ns $=$ not significantly different, ${ }^{*} p<0.05,{ }^{* *} p<$ $0.01,{ }^{* * *} p<0.001$ vs. control group.

\subsection{Cell-based Characterization of New Potent Com- pounds: First Step for Action Modes Determination}

\subsubsection{Evaluation of Cell Viability (Unspecific Cytotoxicity) of the Compounds}

Cytotoxicity of each compound was studied by using the MTT assay. Compounds 1, 3, 4, 9, 10,11, 14, 15, 17, 18 and 19 were not tested due to their low solubility in culture medium. Others could only be tested at concentration of $50 \mu \mathrm{M}$ $(6,8$ and 12). Among the evaluated compounds, 6 and 16 were toxic showing cell viability lower than $90 \%$ at the dose of $100 \mu \mathrm{M}$ (data not shown).

\subsubsection{Determination of Nitric Oxide Production}

Macrophages participate in both non-specific and acquired immune responses [24]. LPS-stimulated macrophage generates a series of inflammatory responses including an enhanced production of NO. As shown in Fig. (6), except compounds $6,7,8$ and 12 , all tested compounds (especially at the highest doses) demonstrated the ability to significantly inhibit NO production in a dose-dependent manner. In particular, the lead compound, VA5-131, showed levels of NO similar to the blank group, that is, a significant inhibition of over $90 \%$. Similarly, compounds $2(100 \mu \mathrm{M})$, and $\mathbf{1 6}(25$ and $50 \mu \mathrm{M}$ ) demonstrated a significant inhibition of over $80 \%$.

\subsubsection{Measurement of Cytokine Production}

Pro-inflammatory cytokines such as TNF- $\alpha$ and IL-6 are produced by macrophages during the inflammatory response in vivo as well as when activated in vitro [25]. The production of these cytokines in LPS-stimulated murine macrophages was determined by means of ELISA. Doses were selected according to the cell viability assay.

As shown in Fig. (7A), all compounds showed a similar behavior compared with VA5-13l, except for compound $\mathbf{1 6}$ at the dose of $50 \mu \mathrm{M}$, which significantly inhibited TNF- $\alpha$ production in an $81 \%$. Compounds $\mathbf{6}, \mathbf{7}$ and $\mathbf{8}$, the most potent chemicals in previous in vivo anti-inflammatory assays, are unable to inhibit TNF- $\alpha$ release. These results suggested that compounds with substituted Bn moieties at position 2 (namely, 6, 7 and 8) would not have this mechanism of action; however, compounds with aliphatic rings (or bulky groups) at this position, such as compound 16, have the ability to inhibit both NO and TNF- $\alpha$ release.

All compounds at the evaluated concentrations significantly inhibited IL-6 production (Fig. 7B). Further studies are needed to determine if these effects are due to a direct inhibition of the production or to an indirect action through inhibition of previous steps of the regulatory cascade implicated in cytokine release. In any case, cytokine networks regulate the inflammatory response and pro-inflammatory cytokines such as IL-6 interferes notably on the regulation of immune reactions and inflammation [6a] therefore its modulation is of great interest in therapeutics.

\subsubsection{Determination of Enzyme Expression by Western Blot Assay}

COX-2 and iNOS have a marked pro-inflammatory function in the development of certain diseases [26]. For this reason, we evaluated the effect on the expression of both enzymes in protein homogenates of RAW 264.7 macrophages stimulated by LPS. As shown in the Fig. (8A), only compounds $2(50$ and $100 \mu \mathrm{M})$ and $7(100 \mu \mathrm{M})$ significantly inhibit the expression of COX-2. Compound 7 (4-FBn derivative) and also the rather close analogs 6 (3FBn) and 8 (4-ClBn) depicted the higher potency in TPA and MPO tests (see Fig. 5). However, compound 6 nor compound 8 inhibited COX-2 expression. Compound $\mathbf{1 6}$ increased its production; an interesting effect that deserves further studies to determine what structural differences of this molecule compared to the other might be responsible for this action. 


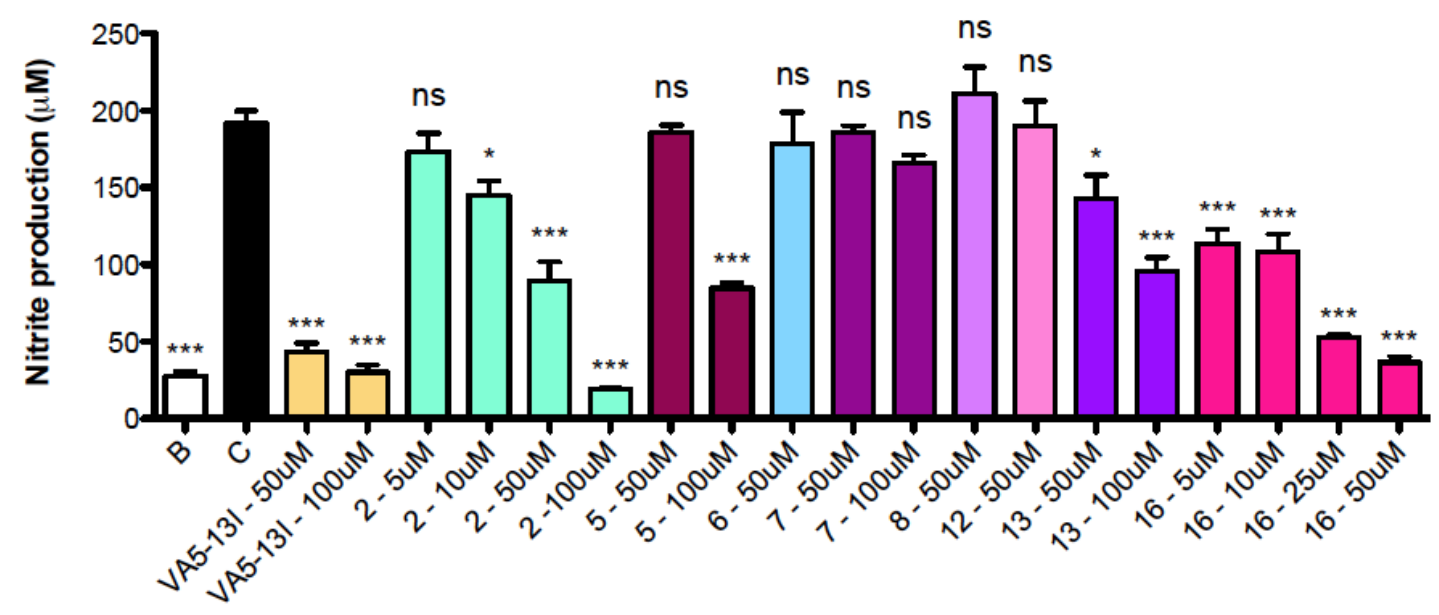

Fig. (6). Effects of the selected compounds on nitric oxide production by RAW 264.7 macrophages. Values are expressed as nitrite production $(\mu \mathrm{M})$ with respect to the control group treated with LPS. Data signify the mean $\pm \mathrm{SD}$ of at least three dissimilar experimentations. $* * \mathrm{P}<$ $0.01, * \mathrm{P}<0.05$ compared with control (Dunnett's t-test).
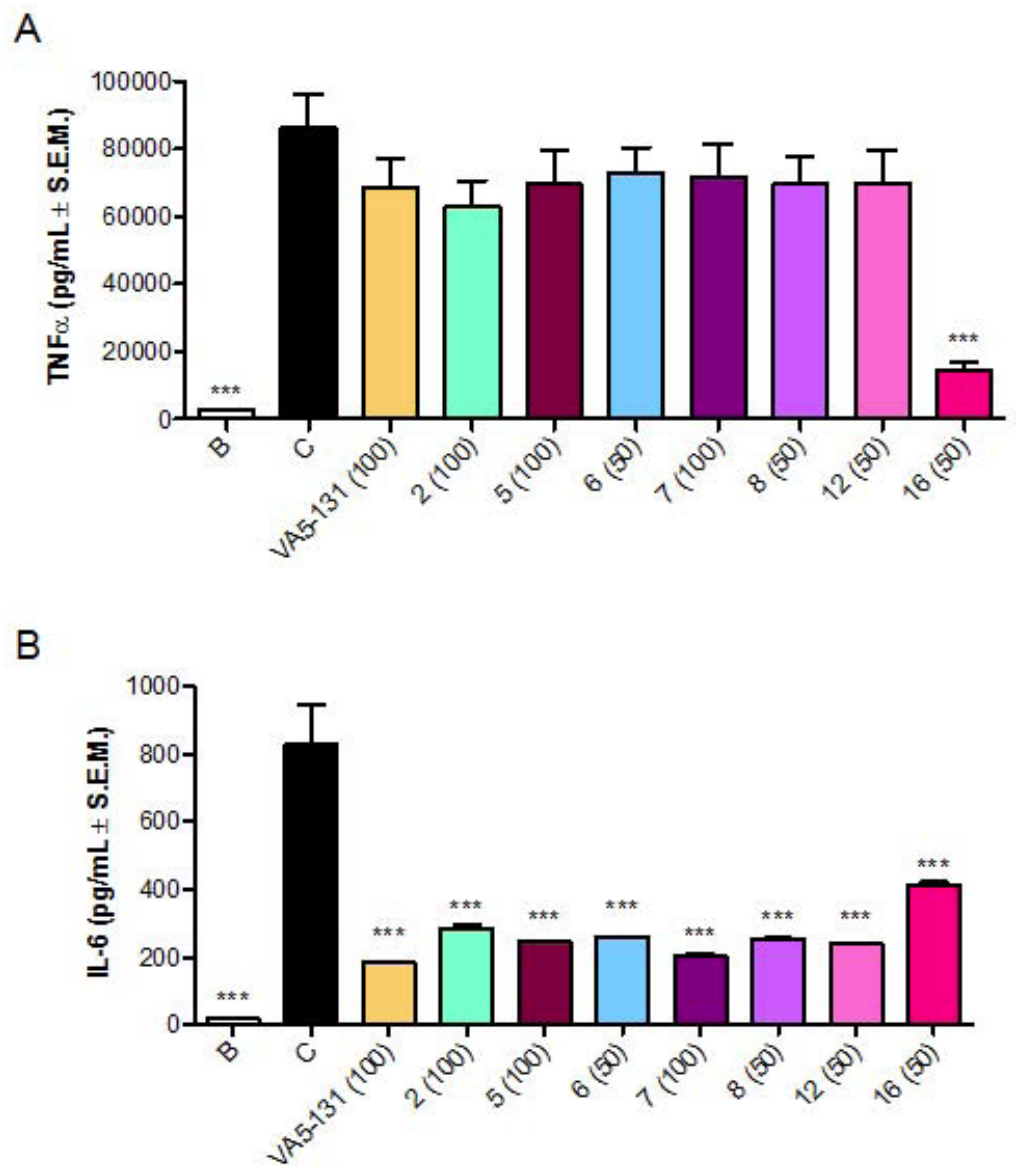

Fig. (7). Overall cytokine production in RAW 264.7 macrophages. Macrophages were treated with each chemical and $1 \mathrm{~h}$ later stimulated with $1 \mu \mathrm{g} / \mathrm{mL}$ for $24 \mathrm{~h}$. After the collection of the supernatant the cytokines were measured in duplicate by ELISA. The C group signifies those macrophages stimulated with LPS $(1 \mu \mathrm{g} / \mathrm{mL})$. Results are expressed as cytokine concentration $\mathrm{pg} / \mathrm{mL} \pm \mathrm{SEM}$ and are demonstrative of three independent experimentations. Differences with the C (control) group were evaluated using a one-way analysis of variance (ANOVA) followed by Dunnett's t-test $(* * * p<0.001)$.

Nevertheless, none of the studied compounds inhibited significantly iNOS expression (Fig. 8B). This outcome suggested that the inhibition of COX-2 expression would be a possible mechanism of action that would explain its antiinflammatory effects.

\section{CONCLUDING REMARKS}

Several adverse effects limit the treatment of inflammatory disorders. Combinations of adequate moieties through the molecular scaffold of 5-nitroindazolinones can create 


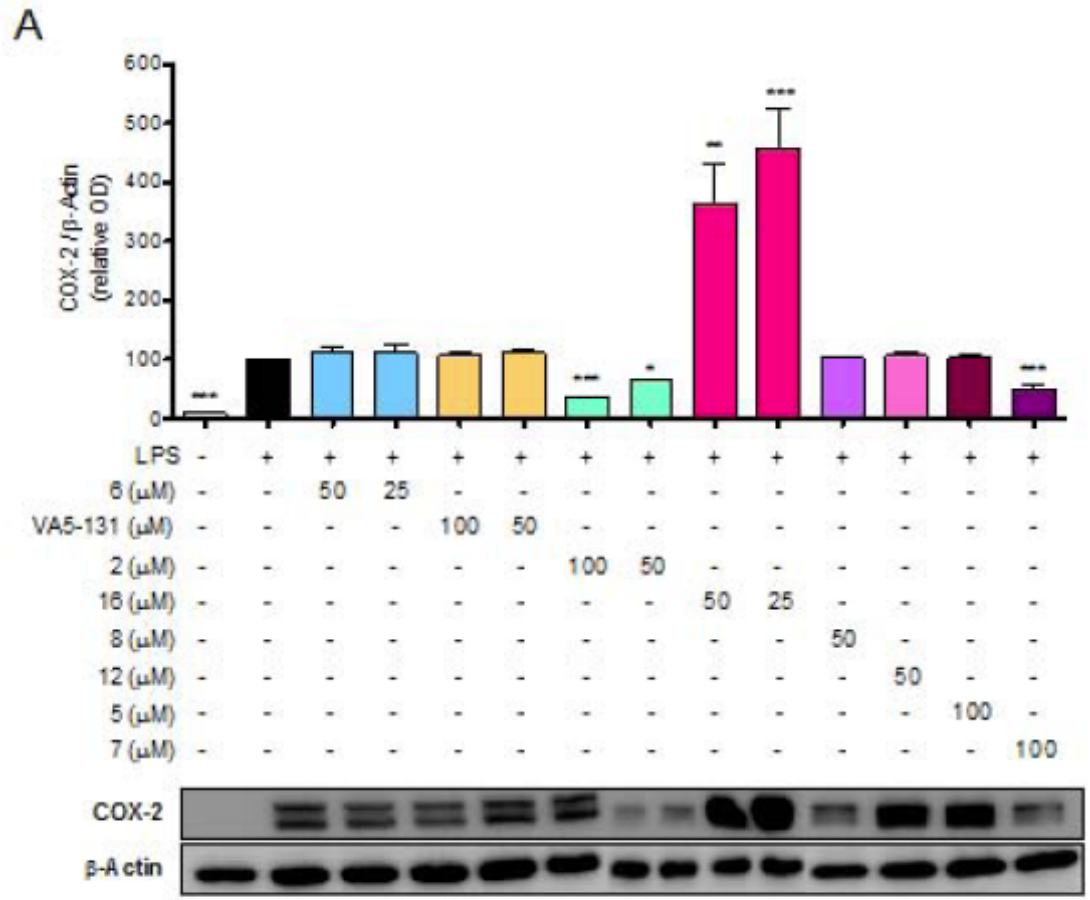

B

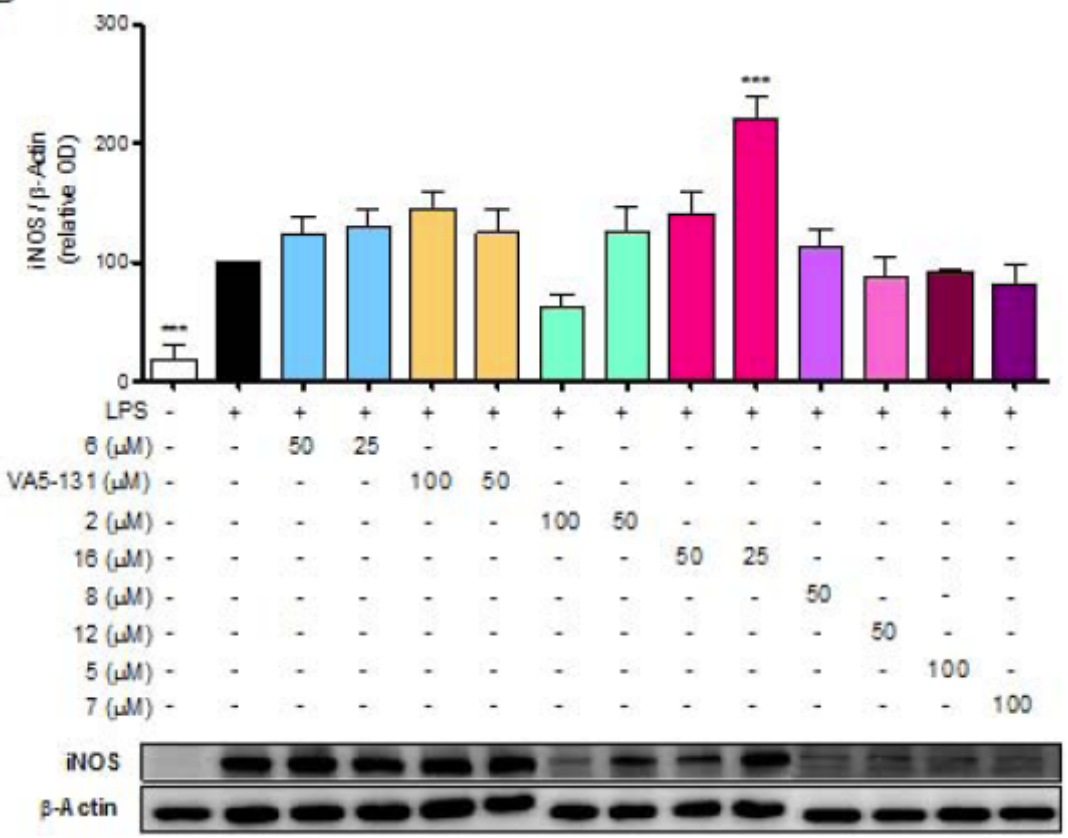

Fig. (8). Effect of the different studied molecules in the levels of iNOS and COX-2 in RAW 264.7 macrophages. The data given are the mean values \pm standard error of the mean (SEM) taken from four independent experimentations to each enzyme. A illustrative test is shown in the lower panel. The histograms signify the data derived from the Western blots following densitometry analysis. In A and B, levels were normalized against $\beta$-actin. $* p<0.05,{ }^{* *} p<0.01,{ }^{* *} p<0.001$, significantly different from the LPS group; Dunnett's t-test.

original entities with superior therapeutic activity (and/or better safety profiles). Various structural analogues of VA5131 were screened for in vivo anti-inflammatory activity. Compounds that exhibited significant zebrafish-based RLM inhibition were prone to anti-inflammatory evaluations on mouse ear edema. Compounds 7 and 8 (4-FBn and 4-ClBn derivatives, respectively) exhibited the best effect in both in vivo tests, comparable with indomethacin, so this prototype appear promising. SAR analysis gives information on the fine relationship relating structure and activity and provides evidences for structural modifications that can enhance the effect. These trends should prove to be an essential guide for the future work. Finally, the in vitro assays indicate that the inhibition of IL-6 production and COX-2 expression could be the mechanism of action for this type of compounds.

Compound 16, with a cycloaliphatic substituent (cyclohexylmethyl) at position 2 of indazolinones ring, was the only one that showed a significant inhibition of TNF- $\alpha$. This 
compound showed anti-inflammatory activity with inhibition value similar to those of indomethacin in TPA assay. Nevertheless, 16 showed not significantly decreased neutrophil infiltration, determined as MPO activity on TPA application test. Finally, this molecule demonstrated: 1) the ability to significantly to inhibit NO production, and 2) at the dose of $50 \mu \mathrm{M}$, significantly inhibited TNF- $\alpha$ production in an $81 \%$.

A new anti-inflammatory drug able to act at multiple targets would be ideal, allowing for synergic action and minimizing toxicity [6b, 27]. Nevertheless, further deeply research of these compounds is needed to improve our knowledge about their mechanism of action and searching for other anti-inflammatory targets. In order to avoid the solubility problems of these compounds certain chemical modifications could be also carried out in the near future.

\section{EXPERIMENTAL SECTION}

\subsection{Ethics Statement}

Zebrafish procedures were performed in accordance with Belgian and European Laws, guidelines and policies for animal experimentation, housing and care (Belgian Royal Decree of 6 April 2010 and European Directive 2010/63/EU on the protection of animals used for scientific purposes of 20 October 2010). The institutional Ethical Committee for Animal Experimentation of the University of Leuven has approved this project with the number P101/2010.

Rodent procedures regarding experimental protocols were approved by the Institutional Ethics Committee of the University of Valencia, (Spain) in accordance with the guidelines established by the European Union on Animal Care (CEE Council 86/609). Female BALB/c female Swiss mice weighing 25-30 g (Harlan Interfauna Iberica, Barcelona, Spain) were used for in vivo experiences. All animals were fed a standard diet ad libitum and housed under a $12 \mathrm{~h}$ light/dark cycle at $22{ }^{\circ} \mathrm{C}$ and $60 \%$ humidity.

\subsection{In Vivo Tests}

\subsubsection{LPS-enhanced Leukocyte Migration Assay in Ze- brafish}

All chemicals were first dissolved in dimethyl sulfoxide [(DMSO) 99.5\% (GC) Sigma-Aldrich)], and then diluted in embryo medium Danieau's 0.3X (50 mM NaCl, $10 \mathrm{mM} \mathrm{KCl}$, $10 \mathrm{mM}$ Hepes, $10 \mathrm{mM} \mathrm{CaCl}, 10 \mathrm{mM} \mathrm{Mg}_{2} \mathrm{SO}_{4}, 30 \mathrm{mM}$ methylene blue). The DMSO final concentration did not reach $1 \%$ in order to prevent damage to the larvae. Lipopolysaccharides from Salmonella typhosa ATCC 10749 (LPS, Sigma-Aldrich) were reconstituted in ionized water (Milli$\mathrm{Q}^{\mathbb{B}}$ ), aliquoted in small vials and kept at $-20{ }^{\circ} \mathrm{C}$ until needed for the assay to stimulate leukocyte migration in larvae.

Along the experiments, transgenic zebrafish of the line fli1: EGFP were used. Once the fertilized eggs were collected, they were reared in embryo medium Danieau's $0.3 \mathrm{X}$ in an incubator at $28^{\circ} \mathrm{C}$. At 20 hours post fertilization (hpf), 1phenyl-2-thiourea (PTU) (Sigma- Aldrich $10 \times(0.03 \%)$ was added to larvae's medium in proportion 1:9 to avoid the melanophores formation in zebrafish embryos and larvae [28].

Toxicological evaluation. Ten 4-dpf zebrafish larvae were incubated at $28{ }^{\circ} \mathrm{C}$ with increasing concentrations of each compound (ranging from $0.1 \mu \mathrm{M}$ to $500 \mu \mathrm{M}$ ). A control with only vehicle (1\% DMSO) and non-treated larvae were also included in this evaluation. The larvae were examined under light microscopy (Carl Zeiss Stemi 2000C) each hour during a period of eight hours and a final evaluation at 24 hours post-incubation. Signs of toxicity were associated to modification in the normal morphology and physiology of larvae and the maximum tolerated concentration (MTC) for each tested sample was determined based on this. All the toxicological evaluations were performed in duplicate using a different group of zebrafish larvae per set of experiments.

Anti-inflammatory experimental procedure. Ten 4-dpf larvae were used per experimental group and controls. The positive controls, indomethacin (Sigma-Aldrich) and negative control (DMSO 1\%), were tested per set of samples. After an initial incubation of one hour, they were anesthetized by immersion in a solution of tricaine $(70 \mu \mathrm{g} / \mathrm{mL})$ to perform a complete tail transaction in the tail tip region. Once tails were cut, larvae were subjected to further incubation for seven hours at $28{ }^{\circ} \mathrm{C}$. At this stage, inclusion of LPS $(10 \mu \mathrm{g} / \mathrm{mL})$ ensures stimulation of the leukocyte migration to the damaged zone. When the incubation time was completed, larvae were fixed overnight in $4 \%$ paraformaldehyde (Sigma-Aldrich) at $4{ }^{\circ} \mathrm{C}$. A series of washes with phosphate buffer saline containing 1\% Tween 20 (PBST) followed the fixation process. The colouring reaction took place using 1 $\mathrm{mL}$ of staining solution of Leucognost POX $^{\circledR}$ (Merck) during 15 minutes. Microscopic evaluation of each larva for every group allowed a semi-quantitative analysis, in which values of RML were expressed for every sample. The value achieved for each of the ten larvae tested for one group is expressed as RLM according the formula: RLM = leukocyte migration of the larva / average leukocyte migration of the negative control (DMSO), finally the average is calculated for each group. RLM $\leq 0.5$ is considered as cutoff point for a significant anti-inflammatory activity $[15,20]$.

\subsubsection{2-O-tetradecanoylphorbol-13-acetate (TPA)- induced Mouse Ear Edema}

Anti-inflammatory experimental test. Topical antiinflammatory activity of the compounds was evaluated following the method reported by Young and De Young [29] with some modifications [30]. Topical application of 2.5 $\mu \mathrm{g} /$ ear of TPA (Sigma-Aldrich, St. Louis, MO, USA) in 20 $\mu \mathrm{L}$ acetone (Panreac, Barcelona, Spain) induced the edema on the right ear $(10 \mu \mathrm{l} / \mathrm{side})$. The same volume of acetone were applied to the right ear of vehicle control animals. Compounds tested and indomethacin (Sigma-Aldrich), used as reference drug, at dose of $0.5 \mathrm{mg} /$ ear dissolved in acetone $(20 \mu \mathrm{L})$ were applied topically to right ear simultaneously with TPA. Four hours after TPA application, the animals were killed by cervical dislocation and right and left ear punches ( $6 \mathrm{~mm}$ diameter $)$ from each animal were taken. The edema was determined by the ear thickness increment. Ear tissues were frozen and stored at $-80{ }^{\circ} \mathrm{C}$ until use. Details of the method have been previously described [31].

Myeloperoxidase (MPO) activity in mouse ear edema tissues was determined according to De Young et al. with modifications [32]. Ear sections were homogenized in 1.5 $\mathrm{mL}$ of $80 \mathrm{mM}$ sodium phosphate buffer (PBS, pH 5.4) containing $\quad 0.5 \%$ hexadecyltrimethylammonium bromide 
(HTAB) and centrifuged. Then $100 \mu \mathrm{L}$ of PBS, $85 \mu \mathrm{L}$ of 22 $\mathrm{mM}$ monopotassium phosphate/disodium phosphate buffer and $15 \mu \mathrm{L}$ of hydrogen peroxide $0.017 \%$ were added to 30 $\mu \mathrm{L}$ of the supernatant. Addition of $30 \mu \mathrm{L}$ of $1.46 \mathrm{M}$ buffer HOAc/NaOAc ( $\mathrm{pH}$ 3.0) stopped the reaction. MPO activity was spectrophotometrically determined at $630 \mathrm{~nm}$. MPO activity is expressed as the amount of enzyme required to convert $1 \mu \mathrm{mol}$ of hydrogen peroxide to water in $1 \mathrm{~min}(\mathrm{U} / \mathrm{g}$ tissue).

\subsection{In Vitro Assays \\ 4.3.1. Cell Culture}

The RAW 264.7 cell line, obtained from the ECACC (Salisbury, UK) were cultured in Dulbecco Modified Eagle's Medium (DMEM) supplemented with 10\% fetal bovine serum, penicillin $(100 \mathrm{U} / \mathrm{mL})$ and streptomycin sulfate $(100$ $\mu \mathrm{g} / \mathrm{mL})$ in a humidified $5 \% \mathrm{CO}_{2}$ atmosphere at $37{ }^{\circ} \mathrm{C}$.

Compounds were dissolved in DMSO $(10 \mathrm{mM}$ stock concentration) and stored at $-20{ }^{\circ} \mathrm{C}$. DMSO $(0.1 \%, \mathrm{v} / \mathrm{v})$ was used as a vehicle control in all experiments and standardized in all samples.

\subsubsection{Cell Viability Assay}

The possible cytotoxicity of the different compounds tested was evaluated with the 3-[4,5-dimethylthiazol-2-yl]2,5-diphenyltetrazolium bromide (MTT) assay. The RAW 264.7 macrophages were exposed to compounds at concentrations 50 and $100 \mu \mathrm{M}$ in a 96-well microplate at various assay times. Then $100 \mu \mathrm{L}$ per well of a $0.5 \mathrm{mg} / \mathrm{mL}$ solution of MTT (Sigma-Aldrich) was added and incubated at $37^{\circ} \mathrm{C}$ until blue deposits were visible. After dissolving the colored metabolite was dissolved in DMSO, absorbance was measured at $490 \mathrm{~nm}$ with a VICTOR ${ }^{\mathrm{TM}} X 3$ Multilabel Plate Reader (PerkinElmer, Shelton, USA). A decrease in absorbance indicated a reduction in cell viability ( $<90$ was considered toxic concentrations).

\subsubsection{Nitric Oxide Determination}

The RAW 264.7 cells were seeded at $5 \times 10^{5}$ cells per well in 24-well microplates. The substances (50 and 100 $\mu \mathrm{M})$ were added to the culture medium $1 \mathrm{~h}$ before the addition of $1 \mu \mathrm{g} / \mathrm{mL}$ LPS. The cultured medium was collected 24 $\mathrm{h}$ after and mixed with an equal volume of Griess reagent (Sigma-Aldrich). An increase of nitrite $\left(\mathrm{NO}_{2}{ }^{-}\right)$in supernatant is indicator of NOS activity. Absorbance was measured at $550 \mathrm{~nm}$.

\subsubsection{Measurement of Cytokine Production}

The RAW 264.7 cells were seeded at $5 \times 10^{5}$ cells per well in 24-well microplates, treated with the substances at two concentrations $(25-50 \mu \mathrm{M}$ or $50-100 \mu \mathrm{M})$ and $1 \mathrm{~h}$ later stimulated with $1 \mu \mathrm{g} / \mathrm{mL}$ LPS. After $24 \mathrm{~h}$ the supernatants were collected and TNF- $\alpha$ and IL- 6 production was quantified using an ELISA kit (eBioscience, San Diego, CA, USA) according to the manufacturer's instructions.

\subsubsection{Western Blot analysis for $\mathrm{COX}-2$ and iNOS}

RAW 264.7 macrophages $\left(1.5 \times 10^{6}\right.$ cells per well $)$ were co-incubated in a 6-well culture plate $(1 \mathrm{~mL})$ with $1 \mu \mathrm{g} / \mathrm{mL}$ of LPS at $37{ }^{\circ} \mathrm{C}$ for $24 \mathrm{~h}$ in the presence of test compounds or vehicle. Cellular lysates were obtained with lysis buffer (1\% Triton X-100 $1 \mathrm{~mL}, 1 \%$ deoxycholic acid $1 \mathrm{~g}, 20 \mathrm{mM}$ $\mathrm{NaCl} 120 \mathrm{mg}, 25 \mathrm{mM}$ Tris- $\mathrm{HCl} 390 \mathrm{mg}$, and 1 tablet of complete Mini EDTA-free protease inhibitor cocktail from Roche). After centrifugation $(10,000 \times \mathrm{g}, 10 \mathrm{~min})$, the proteins present in the supernatants were quantified [33]. Identical amounts of protein $(30 \mu \mathrm{g})$ were then loaded onto $10 \%$ sodium dodecyl sulfate polyacrylamide electrophoresis gel and were relocated onto polyvinylidene difluoride membranes at $125 \mathrm{~mA}$ for $90 \mathrm{~min}$. The membranes were then blocked in PBS-Tween 20 containing 3\% w/v defatted milk. For iNOS and COX-2, the membranes were incubated with anti-iNOS polyclonal antibody (1/1000) and anti-COX-2 polyclonal antibody $(1 / 1000)$, respectively (both obtained from Cayman, Ann Arbor, MI, USA). For $\beta$-actin, used as a loading control, the membranes were incubated with anti- $\beta$ actin polyclonal antibody (1/12000) (Sigma-Aldrich). The blots were washed and incubated with peroxidase-conjugate anti-rabbit immunoglobulin G (1/20000 dilution; Cayman). The immunoreactive bands were visualized with the aid of an enhanced chemiluminescence system (GE Healthcare, Fairfield, CT, USA).

Software. Images for Western blot experiments were acquired with the image analysis system LAS-3000 mini (Fujifilm, Tokyo, Japan). Digital images were processed, and band density measurements were made with the aid of a Multi Gauge V3.0 software package (Fujifilm).

\subsection{Statistical Analysis}

Statistical analysis was achieved by means of one-way analysis of variance (ANOVA) and Dunnett's t-test. The results are presented as the mean \pm S.E.M. GraphPad Prism 4.0 software (GraphPad Software Inc., San Diego, CA, USA) was used for all calculations.

\subsection{Computational Procedures for SAR Analysis}

The NSGs have been created and represented as described earlier by means of SARANEA software [18]. SARANEA is openly accessible without constraints via the following URL: http:/www.lifescienceinformatics.uni-bonn.de/ (see the Downloads Section).

As a fingerprint for compound evaluation in SARANEA study, MACCS has been used. These molecular descriptor calculations were achieved using MOLFIP (acronym for MOLecular FIngerPrints), a module of TOMOCOMD$\boldsymbol{C A R D D}$ that offers fast and low-computational-cost calculations of the 8 fingerprint families. Using the Chemistry Development Kit (CDK), these fingerprints were performed in our MOLFIP program [34].

\section{CONSENT FOR PUBLICATION}

Not applicable.

\section{CONFLICT OF INTEREST}

The authors declare no conflict of interest, financial or otherwise. 


\section{ACKNOWLEDGEMENTS}

Authors acknowledge the Laboratory for Molecular Biodiscovery at the University of Leuven (Belgium) for kind hospitality. S-M, D was financed by a PhD fellowship from the Vlaamse Interuniversitaire Raad (VLIR) linked to a VLIR-UOS cooperation program with the University "Martha Abreu", Cuba. C-M, ML was financed by a PhD fellowship from the Vlaamse Interuniversitaire Raad (VLIR) linked to the VLIR-UOS project "Pharmacological Characterization of Medicinal Plants from the South of Ecuador". M-P, Y. thanks to the program 'Chancellor Grant USFQ' for partial support of this research (Project no 5513).

\section{REFERENCES}

[1] V. Staniforth, S. Y. Wang, L. F. Shyur, N. S. Yang, J Biol Chem 2004, 279, 5877-5885.

[2] G. R. Smith, S. Missailidis, J Inflammation 1. J Inflamm (London) 2004, 1:3.

[3] F. Berenbaum, Curr Opin Rheumatol 2004, 16, 616-622.

[4] H. Okamoto, A. Kobayashi, J. Inflammation 2011, 8:21.

[5] H. Halliday, S. R. Robinson, C. Shepherd, J. Kril, Clin. Exp. Pharm. Phys. 2000, 27, 1-8.

[6] aI. B. McInnes, G. Schett, Nat Rev Immunol 2007, 7, 429-442; bY. Wang, C. Yu, Y. Pan, J. Li, Y. Zhang, F. Ye, S. Yang, H. Zhang, X. Li, G. Liang, PLoS ONE 2011, 6, e24377.

[7] aC. Xiao, S. Ghosh, Adv Exp Med Biol 2005, 560, 41-45; bY. Yamamoto, R. B. Gaynor, Trends Biochem Sci 2004, 29, 72-79.

[8] aM. Di Rosa, A. Ialenti, A. Ianaro, L. Sautebin, Prostaglandins Leukot Essent Fatty Acids 1996, 54, 229-238; bS. E. Chesrown, J. Monnier, G. Visner, H. S. Nick, Biochem. Biophys. Res. Commun 1994, 200, 126-134; cL. C. Denlinger, P. I. Fisette, K. A. Garis, G. Kwon, A. Vazquez-Torres, A. D. Simon, B. Nguyen, R. A. Proctor, P. J. Bertics, J. A. Corbett, J Biol Chem 1996, 271, 337-342.

[9] A. Weisz, I. Cicatiello, H. Esumi, Biochem J 1996, 316, 209-215.

[10] aT. J. Guzik, R. Korbut, T. Adamek-Guzik, J Physiol Pharmacol 2003, 54, 469-487; bA. L. Bastos-Pereira, D. Lugarini, A. de Oliveira-Christoff, T. V. Avila, S. Teixeira, A. D. Pires, M. N. Muscara, S. M. Cadena, L. Donatti, H. C. da Silva de Assis, A. Acco, Cancer Chemother. Pharmacol. 2009, 65 267-276; cQ. Wang, K. Birod, C. Angioni, S. Grosch, T. Geppert, P. Schneider, M. Rupp, G. Schneider, PLoS ONE 2011, 6, e21554.

[11] A. Peretz, N. Degani-Katzav, M. Talmon, E. Danieli, A. Gopin, E. Malka, R. Nachman, A. Raz, D. Shabat, B. Attali, PLoS ONE 2007, 2, e1332.

[12] A. Peretz, N. Degani, R. Nachman, Y. Uziyel, G. Gibor, Mol. Pharmacol. 2005, 67, 1053-1066.

[13] L. Li, G. Rossoni, A. Sparatore, L. C. Lee, P. Del Soldato, P. K. Moore, Free Radic Biol Med 2007, 42 706-719.
[14] N. A. Punchard, C. J. Whelan, I. Adcock, J Inflamm (Lond) 2004, $1: 1$.

[15] Y. Marrero-Ponce, D. Siverio-Mota, M. Gálvez-Llompart, M. C. Recio, R. M. Giner, R. García-Domènech, F. Torrens, V. J. Arán, M. L. Cordero-Maldonado, C. V. Esguerra, P. A. M. de Witte, A. D. Crawford, Eur. J. Med. Chem. 2011, 46, 5736-5753.

[16] aY. Marrero-Ponce, A. Huesca-Guillen, F. Ibarra-Velarde, $J$ Theor. Chem. (Theochem) 2005, 717, 67-79; bY. Marrero-Ponce, M. Iyarreta-Veitia, A. Montero-Torres, C. Romero-Zaldivar, C. A. Brandt, P. E. Avila, K. A. Kirchgatter, Y. Machado, J. Chem. Inf. Comput. Sci. 2005, 45, 1082-1100.

[17] D. Siverio-Mota, L. Vicet-Muro, Y. Rivero-Guerra, M. L. SueiroOyarzun, Y. Marrero-Ponce, V. J. Arán, Rev. Cub. Farm. 2012, 46.

[18] aE. Lounkine, M. Wawer, A. M. Wassermann, J. Bajorath, $J$ Chem. Inf. Model. 2010, 50, 68-78; bM. Wawer, L. Peltason, N. Weskamp, A. Teckentrup, J. Bajorath, J. Med. Chem. 2008, 51, 6075-6084.

[19] M. C. Vega, M. Rolón, A. Montero-Torres, C. Fonseca-Berzal, J. A. Escario, A. Gómez-Barrio, J. Gálvez, Y. Marrero-Ponce, V. J. Arán, Eur. J. Med. Chem. 2012, 58, 214-227.

[20] M. L. Cordero-Maldonado, D. Siverio-Mota, L. Vicet-Muro, W.-A. I. M., C. V. Esguerra, P. A. M. de Witte, A. D. Crawford, J. Inflammation 2012, Submitted for Revision.

[21] A. D. Crawford, C. V. Esguerra, P. A. M. de Witte, Planta Medica 2008, 74, 624-632.

[22] J. M. Young, B. M. Wagner, D. A. Spires, J Invest Dermatol 1983, $80,48-52$.

[23] I. Posadas, M. Bucci, F. Roviezzo, A. Rossi, L. Parente, L. Sautebin, G. Cirino, British J. Pharm. 2004, 142, 331-338.

[24] R. Medzhitov, Cell 2010, 140, 771-776.

[25] M. Feldmann, F. M. Brennan, R. N. Maini, Annu Rev Immunol 1996, 14, 397-402.

[26] R. Paduch, M. Kandefer-Szerszeń, Cancer Microenviron 2011, 4, 187-198.

[27] P. Longhin-Bosquesi, T. Ferreira-Melo, E. Oliveira-Vizioli, J. dos Santos, M. Chung, Pharmaceuticals 2011, 4, 1450-1474.

[28] J. Karlsson, J. von Hofsten, P. Olsson, Mar. Biotechnol. 2001, 3 522-527.

[29] L. M. De Young, J. B. Kheifets, S. J. Ballaron, J. M. Young, Agents Actions 1989, 26, 335-341.

[30] M. Payá, M. Ferrándiz, M. J. Sanz, G. Bustos, R. Blasco, J. L. Ríos, M. J. Alcaraz, Phytother. Res 1993, 7, 159-162.

[31] R. M. Giner, M. L. Villalba, M. C. Recio, S. Máñez, M. CerdáNicolás, J. L. Ríos, Eur. J. Pharmacol 2000, 389, 243-252.

[32] J. M. Young, L. M. De Young, in Modern Methods in Pharmacology. Pharmacological Methods in the Control of Inflammation (Eds.: S. Spector, N. Back), Alan R Liss Inc., New York, 1989, pp. 215-231.

[33] B. L. Slomiany, A. Slomiany, J Physiol Pharmacol 2002, 53, 159 169.

[34] C. Steinbeck, Curr. Pharm. Des. 2006, 12, 2111-2120.

DISCLAIMER: The above article has been published in Epub (ahead of print) on the basis of the materials provided by the author. The Editorial Department reserves the right to make minor modifications for further improvement of the manuscript. 